\title{
THE EFFECTIVENESS OF VIDEO ASSISTED TEACHING PROGRAMME ON KNOWLEDGE REGARDING PERCUTANEOUS TRANSLUMINAL CORONARY ANGIOPLASTY AMONG NURSING STAFF
}

Neelam Shrestha, ${ }^{1}$ Pragya Shrestha, ${ }^{1}$ Roshan Dev Yadav ${ }^{2}$

\begin{abstract}
INTRODUCTION

Percutaneous Transluminal coronary Angioplasty (PTCA) is an increasingly important revascularization strategy in coronary artery disease management and can be an emergent planned or rescue procedure. Nurses play a critical role in delivering care both in the independent and collaborative contexts of PTCA management. To improve the care given to patients, it is important to base practice on high level evidence. The study was carried out to assess the knowledge regarding percutaneous transluminal coronary angioplasty among nursing staff and to evaluate the effectiveness of video assisted teaching programme.
\end{abstract}

\section{MATERIALAND METHODS}

Quasi experimental one group pre-test post-test research was done. The target population for the study were nursing staff working in Universal College of Medical Sciences (UCMS), Bhairahawa and those who were willing to participate were included in the study and non-willing staff were excluded. The total duration of study was three months from 25/07/2018 to 22/10/2018. Convenient sampling technique was used for the study. Among 102 nursing staffs, 62 nursing staff were participated in the study. The time taken to complete the demographic data and questionnaire was 20-30 minutes. On the same day after the pre-test video assisted teaching programme was administered to the subject to assess the knowledge regarding Percutaneous Transluminal coronary angioplasty. Post-test was conducted with the same questionnaire on the seventh day of pre-test. Data was collected using structured questionnaire. Statistical analysis was done using SPSS version 20.0 .

\section{RESULTS}

The findings of the study revealed that only $1.6 \%$ of the nurses had adequate level of knowledge before video assisted teaching programme which increased to $64.5 \%$ in post-test.

\section{CONCLUSION}

The knowledge score of most of the nurses on PTCA was moderate before the administration of video assisted teaching programme whereas as most of the nurses had adequate knowledge score after the teaching. There was overall gain in knowledge score following the video assisted teaching programme.

KEYWORDS Knowledge, Nurses, PTCA, Video assisted teaching

1. Universal College of Nursing Sciences, Bhairahawa, Nepal

2. Lumbini Eye Institute(NAMS), Bhairahawa, Nepal

DOI: http//doi.org/10.3126/jucms.v7i2.27140

For Correspondence

Neelam Shrestha

Universal College of Nursing Sciences

Bhairahawa, Nepal

Email:neelamshrestha34@gmail.com 


\section{INTRODUCTION}

An estimate 17.5 million people died from CVD in 2012 representing $31 \%$ of all global death of these death an estimated 7.4 million were due to coronary heart disease. ${ }^{1}$ Cardiovascular diseases are major and growing contributors to mortality and disability in South Asia. Cardiovascular disease refers to any disease that affects the cardiovascular system, principally cardiac disease, vascular diseases of the brain and kidney, and peripheral arterial disease. The causes of cardiovascular disease are diverse but atherosclerosis and hypertension are the most common. Coronary heart disease is one of them, as well as there is many treatment for coronary heart disease, Percutaneous Transluminal Coronary Angioplasty (PTCA) is one of the treatment of this problem. ${ }^{2,3}$ PTCA is an increasingly important revascularization strategy in coronary artery disease management and can be an emergent, planned or rescue procedure. ${ }^{4}$ Nurses play a critical role in delivering care both in the independent and collaborative contexts of PTCA management. To improve the care given to patients, it is important to base practice on high level evidence. Over recent decades, technological individuals undergoing advances adjuvant therapies and new indications for stenting have increased the use of this vascularisation modality. ${ }^{5}$

The process of caring for the patient population has changed dramatically over the past years, with many of the changes being driven by an evolution in the knowledge base underlying nursing practice. ${ }^{6}$ As a Nurse who will work in the cardiac catheterization laboratory of a tertiary level hospital in performing emergent, planned and rescue procedures; this study is much needed to improve the standard of care given to patients undergoing PTCA. So, this study was done to assess the knowledge regarding percutaneous transluminal coronary angioplasty among nursing staff and to evaluate the effectiveness of video assisted teaching on knowledge regarding percutaneous transluminal coronary angioplasty among nursing staff.

\section{MATERIAL AND METHODS}

Quasi experimental one group pre-test post-test research was carried out at UCMS, Bhairahawa. Post-test was carried out one week after video assisted teaching. Ethical clearance was obtained from research committee of UCMS, Bhairahawa and written informed consent was obtained from all the participants. The target population for the study is comprised of the nursing staff working in UCMS, Bhairahawa. Nursing staffs working in UCMS, Bhairahawa were included in the study and non-willing staff were excluded. Sixty two participants were selected using convenient sampling. Data was collected using structured questionnaire. Statistical analysis was done using SPSS version 20.0.

\section{RESULTS}

Table 1. Nurses' score on pre and post-test

\begin{tabular}{|c|c|c|c|c|}
\hline Score & Statement & Range & S.D. & Mean \\
\hline Pre-test & 28 & $6-21$ & 3.96 & $13.63(48.7 \%)$ \\
\hline \multirow[t]{3}{*}{ Post-test } & 28 & $7-26$ & 5.21 & 19.77 \\
\hline & & & & $(70.6 \%)$ \\
\hline & \multicolumn{2}{|c|}{ Effectiveness } & & $6.14(21.9 \%)$ \\
\hline
\end{tabular}

Table 1 shows there was significant association between video assisted teaching programme and improvement in mean score $(p<0.001)$

Table 2. Nurses' level of knowledge regarding PTCA $n=62$

\begin{tabular}{|c|c|c|c|c|c|}
\hline \multirow[t]{2}{*}{ Level of knowledge } & \multicolumn{2}{|c|}{ Number of participants } & \multicolumn{2}{|c|}{$\begin{array}{l}\text { Number of } \\
\text { participants }\end{array}$} & \multirow[t]{2}{*}{ P value } \\
\hline & Pre-test & (percent) & Post-test & (percent) & \\
\hline Inadequate (score $<10$ ) & 16 & $25.8 \%$ & 5 & $8.1 \%$ & \\
\hline Moderate (score 10-19) & 45 & $72.6 \%$ & 17 & $27.4 \%$ & 0.001 \\
\hline Adequate (score $\geq 20$ ) & 1 & $1.6 \%$ & 40 & $64.5 \%$ & \\
\hline Total & 62 & $100 \%$ & 62 & $100 \%$ & \\
\hline
\end{tabular}

Table 2 shows $1.6 \%$ had adequate level of knowledge, $72.6 \%$ had moderate and $25.8 \%$ had inadequate level of knowledge regarding PTCA before video assisted teaching programme while $64.5 \%$ had adequate level of knowledge, $27.4 \%$ had moderate and $8.1 \%$ had inadequate level of knowledge regarding PTCA before video assisted teaching programme. There was statistically significant improvement in the mean score of after video assisted teaching programme.

Table 3. Duration of nurses' experience and pre-test $n=62$

\begin{tabular}{lll}
\hline $\begin{array}{l}\text { Experience in } \\
\text { years }\end{array}$ & $\mathrm{N}$ & Mean pre-test score \\
\hline$<1$ & 13 & 11.69 \\
$1-3$ & 20 & 14.10 \\
$>3$ & 29 & 14.17 \\
\hline
\end{tabular}

Table 3 shows there was no significant association between duration of experience and pre-test score $(\mathrm{P}=0.14)$

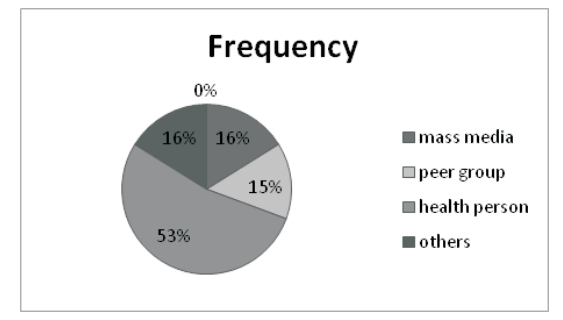

Figure 1. Source of information regarding PTCA 
As shown in Figure 1, 53\% of participants had information of PTCA from health persons, $16 \%$ had information of PTCA from mass media and others and $15 \%$ had information of PTCA from peer group.

\section{DISCUSSION}

Finding of the study showed that most of the nurses $(72.6 \%)$ had intermediate level of knowledge and only one participant (1.6\%) had adequate knowledge regarding PTCA before video assisted teaching programme while $25.8 \%$ had inadequate knowledge. The mean pre-test score was $48.7 \%$ 13.63 (SD 3.96) and the mean post-test score was $70.6 \%$ 19.77 (SD 5.21). There was statistically significant improvement in the mean score of after video assisted teaching programme. Improvement of $21.9 \%$ was achieved in mean score in this study. This finding was consistent with study by Mishra $\mathrm{M}$ et $\mathrm{al}^{7}$ where pre-test score was $40 \%$ that improved to $83.31 \%$. Though both studies showed improvement in post-test knowledge score, the latter had marked improvement in the mean score percentage of $43.31 \%$, which may be due to the fact that the participants in their study were nurses working in cardiac unit. Similar to this study most of the participants had intermediate knowledge, none had adequate knowledge in pre-test and none had inadequate knowledge in post-test after intervention.

The effectiveness of video assisted teaching programme was also consistent with study by Lukose BS et $\mathrm{al}^{8}$ where the knowledge scores of staff nurses regarding the pre and post procedural nursing care of PTCA had revealed that, post-test mean knowledge score was found higher $23.58(78.6 \%)$ and $\mathrm{SD}$ of 2.52 when compared with pre-test mean knowledge score which was $13.28(44.27 \%)$ with SD of 2.48 . The mean effectiveness score was $10.3(34.33 \%)$ with SD of 2.53 . The results of these studies indicate the effectiveness of video assisted teaching programme in improving knowledge of the staff nurses.

In this study most of the nurses were experienced for more than three years where as only 13 had experience of less than one year and 20 had experience in between. Mean pre-test score achieved by nurses experienced for more than three years was $14.17(50.6 \%)$, and that of nurses with less experience $(<1$ year) was only $11.69(41.75 \%)$. Though this finding was statistically not significant, was consistent with study by Chanu LS et $\mathrm{al}^{9}$ which showed more experienced nurses had more knowledge regarding PTCA as compared to less experienced nurses. Not having a control group and small sample size were the main limitations of the study. moderate before the administration of video assisted teaching programme whereas most of the nurses had adequate knowledge score after the teaching. There was overall gain in knowledge score following the video assisted teaching programme. Though nurses with more experience had higher mean pre-test score it was not significant statistically. Video assisted teaching programme was beneficial in improving the knowledge of nurses regarding PTCA.

\section{ACKNOWLEDGEMENTS}

Nursing staff, UCMS.

\section{REFERENCES}

1. World Health Organization. Factsheet of cardiovascular disease.2012 June. Available from: URL:http://www.who.int. mediacentre/factsheets.

2. Hall RJ, Mathur VS, Massumi A, Garcia E, Fighali S. Percutaneous transluminal coronary angioplasty update. Tex Heart Inst J. 1984;11(1):10-6.

3. Sanchis-Gomar F, Perez-Quilis C, Leischik R, Lucia A. Epidemiology of coronary heart disease and acute coronary syndrome. Ann Transl Med. 2016;4(13):256.

4. Gupta R, Gupta V. P. Percutaneous Transluminal coronary angioplasty in India: lessons from Jaipur Heart Watch. Current Science. 2009Aug; 97 (3).

5. Deepa R. K, Aravind. K, Mohan. V. treatment of coronary artery disease. Current Science. 2002 Dec; 83 (12): 1497-1505.

6. Capewell S, Morrison C.E, McMurray J.J. Contribution of modern cardiovascular treatment and risk factor changes to the decline in coronary heart disease mortality in Scotland between 1975 and 1994. Heart. 1999;81:380-386.

7. Mishra M, Chavda A, Kumar N. Evaluate The Effectiveness Of Self Instructional Module On Knowledge Regarding Coronary Angioplasty Among Staff Nurses Working In Cardiac Unit At Selected Hospitals Udaipur City, Rajasthan. IOSR-JNHS. 2018;7(4):32-37.

8. Lukose BS, Gireesh GR, Sachina BT. Staff nurses knowledge on PTCA: an evaluative study. American International Journal of Research in Humanities, Arts and Social Sciences. 2014;8(1):8082.

9. Chanu LS, Chetia P, Mukhim BM. A study to assess the knowledge and practice among staff nurses regarding patient safety after cardiac catheterization with a view to develop a pocket reference on patient safety, after cardiac catheterization at selected hospitals Guwahati, Assam. Indian Journal of Applied Research. 2018;8(7):46-47.

\section{CONCLUSION}

The knowledge score of most of the nurses on PTCA was 